\title{
Aspectos do Comportamento de Polímeros em Condições de Incêndio.
}

\author{
Jorge B. Gallo e José A. M. Agnelli.
}

Resumo: No presente trabalho apresentaremos uma revisão do comportamento dos polímeros quando queimados, procurando enfocar o antagonismo comumente observado entre os aspectos de retardância de chama e emissão de fumaça dos compostos desenvolvidos com vistas à prevenção de incêndio. Apresentaremos também uma breve descrição de alguns testes comumente empregados e uma lista das principais normas internacionais, relevantes para a caracterização dos materiais em relação ao fogo.

Palavras-chave: Inflamabilidade de polímeros, emissão de fumaça, retardantes de chama.

\section{Introdução}

O crescente uso de materiais políméricos, aliado às diversas tragédias que se sucedem a cada ano envolvendo incêndios em ambientes domésticos ou coletivos, têm colocado na ordem do dia a necessidade urgente de se estabelecer códigos, leis e normas que permitam cobrir as carências de orientação, fiscalização e controle quanto ao uso de polímeros tanto em materiais de construção, quanto em móveis, equipamentos e acessórios que preenchem as diferentes edificações. Neste contexto, os veículos de divulgação científica e tecnológica adquirem grande importância no sentido de chamar as atenções para as diversas possibilidades de aperfeiçoamento dos polímeros quanto à prevenção de incêndio.

\section{0 processo da Queima ${ }^{[1,2,3]}$}

O processo da queima de um polímero pode ser dividido nas cinco etapas ilustradas na figura 1

\section{Etapa I: Aquecimento}

Calor de uma fonte externa é fornecido ao material que progressivamente tem a temperatura aumentada. A transferência de calor pode se dar por contato direto com chama, por contato com gases quentes ou ainda por condução através de um corpo sólido

Os principais fatores envolvidos nesta etapa são: Calor específico, Condutividade térmica e Calor latente envolvido em eventuais mudanças de fase.

\section{Etapa II: Pirólise}

Os diferentes componentes do material polimérico atingem suas temperaturas de decomposição (Tabela 1) e começam a liberar uma ou mais das seguintes substâncias :

- Gases combustíveis, tais como alcanos, alcenos, formaldeido e monóxido de carbono;

- Gases não combustíveis, tais como vapor d'água e dióxido de carbono; 


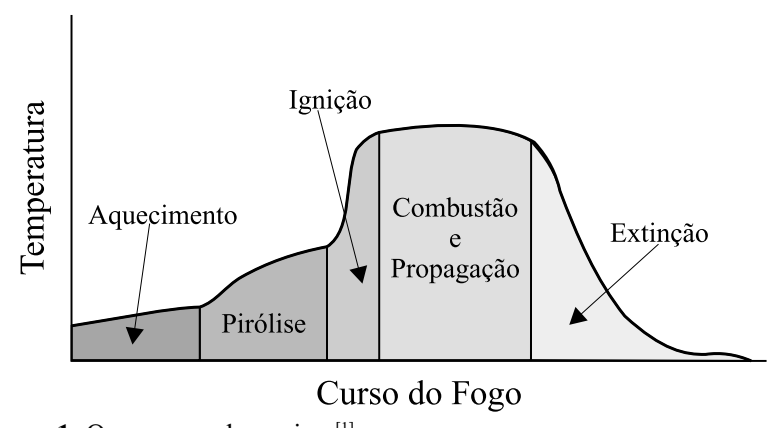

Figura 1. O processo da queima ${ }^{[1]}$

- Gases corrosivos, tais como cloreto de hidrogênio e brometo de hidrogênio;

- Líquidos, usualmente fragmentos das cadeias poliméricas;

- Partículas sólidas tais como fuligem, fibra de vidros e cargas minerais;

- Radicais livres.

As diferentes combinações físicas destas substâncias é que darão origem à fumaça.

O principal fator envolvido nesta etapa é a temperatura de início de pirólise de cada componente.

$\mathrm{Na}$ maioria dos casos, a pirólise ocorre por um mecanismo de radicais livres, iniciado por traços de oxigênio ou outras impurezas oxidantes, que são incorporadas pelos polímeros durante seu processamento. O processo envolve a formação de grupamentos hidroperóxidos, $(\mathrm{ROOH})$, cuja decomposição produz as espécies altamente reativas $\mathrm{H} \cdot \mathrm{e} \mathrm{HO}$, importantes como veremos nos estágios mais avançados da queima.

É ilustrado abaixo, um possível mecanismo de pirólise para as poliolefinas.

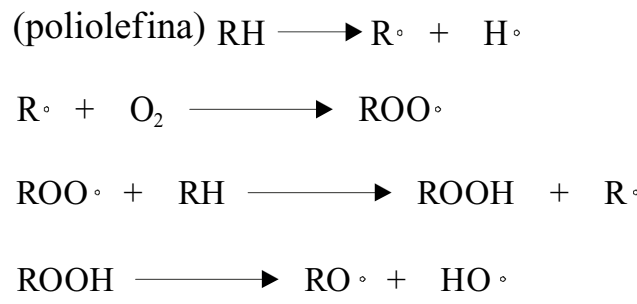

Na presença de oxigênio em concentração suficiente, as reações 2 e 3 formam um ciclo fechado, que acelera grandemente o processo, dado que as mesmas ocorrem a velocidades muito superiores à da reação 1 . $O$ resultado final é a formação de um grande número de diferentes espécies químicas, tais como: variados hidrocarbonetos de baixo peso molecular e os radicais livres altamente reativos $\mathrm{H} \cdot$ e $\mathrm{HO}$. Tais espécies se dirigem à chamada zona de queima gasosa onde se inicia o próximo estágio.

\section{Etapa III:Ignição}

Na medida em que se difundem a partir da superfície do material polimérico, os produtos da pirólise encontram-se com oxigênio, que se difunde em sentido contrário, numa região que poderíamos denominar de zona de queima gasosa, onde as condições de temperatura e concentração de gases combustíveis e de oxigênio atingem níveis tais que permitem a ignição por intermédio de uma fonte externa de calor ou, se a temperatura for suficientemente alta, por autoignição. A temperatura na qual o primeiro fenômeno ocorre é denominada ponto de fulgor, enquanto a temperatura na qual o segundo ocorre é denominada ponto de ignição. Tais temperaturas podem ser determinadas experimentalmente pelo procedimento ASTM D1929, como foram os dados da Tabela 2 .

Os principais fatores que influenciam esta etapa são as temperaturas de ignição e de autoignição e o chamado índice de oxigênio, definido como a concentração mínima de oxigênio necessária para sustentar a combustão (vide ítem índice de oxigênio).

É dado abaixo um possível mecanismo de ignição para o metano.

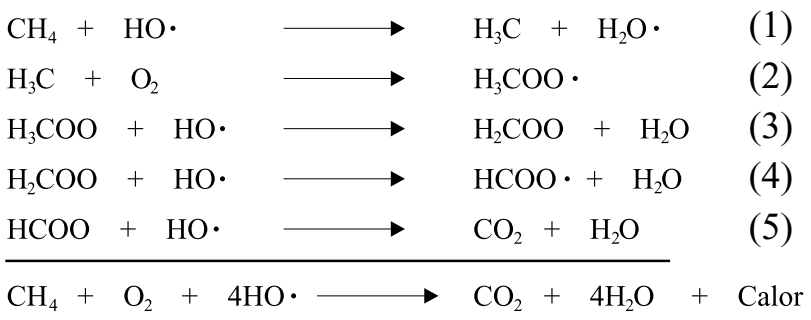

Reações muito parecidas com estas podem ser escritas para o radical $\mathrm{H}$.

Tabela 1. Temperatura de decomposição de alguns polímeros ${ }^{[2]}$

\begin{tabular}{lclc}
\hline \multicolumn{1}{c}{ Polímero } & $\begin{array}{c}\text { Temperatura de } \\
\text { decomposição }\left({ }^{\circ} \mathbf{C}\right)\end{array}$ & \multicolumn{1}{c}{ Polímero } & $\begin{array}{c}\text { Temperatura de } \\
\text { decomposição }\left({ }^{\circ} \mathbf{C}\right)\end{array}$ \\
\hline Polietileno & $340-440$ & Poli(metil metacrilato) & $180-280$ \\
Polipropileno & $320-400$ & Poliacrilonitrila & $250-300$ \\
Poliestireno & $300-400$ & Poliamida 6 & $300-350$ \\
Poli(cloreto de vinila) & $200-300$ & Poliamida 66 & $320-400$ \\
Poli(tetraflúor-etileno) & $500-550$ & Celulose & $280-380$ \\
\hline
\end{tabular}


Tabela 2. Pontos de Fulgor e de Ignição de alguns polímeros ${ }^{[2]}$

\begin{tabular}{lcc}
\hline \multicolumn{1}{c}{ Polímero } & $\begin{array}{c}\text { Ponto de Fulgor } \\
\left({ }^{\mathbf{0}} \mathbf{C}\right)\end{array}$ & $\begin{array}{c}\text { Ponto de Ignição } \\
\left({ }^{\circ} \mathbf{C}\right)\end{array}$ \\
\hline Polietileno & 340 & 350 \\
Polipropileno & 320 & 350 \\
Poliestireno & 350 & 490 \\
Poli(cloreto de vinila) & 390 & 450 \\
Poli(tetrafluoretileno) & 560 & 580 \\
ABS & 390 & 480 \\
Poli(metil metacrilato) & 300 & 430 \\
Poliacrilonitrila & 480 & 560 \\
Poliamida 6 & 420 & 450 \\
Poliamida 66 & 490 & 530 \\
Poliuretano, Espuma & 310 & 415 \\
Rígida & & 400 \\
Algodão & 210 & \\
\hline
\end{tabular}

\section{Etapa IV: Combustão e Propagação}

Os radicais livres gerados na pirólise desempenham importante papel na etapa de ignição, desencadeando reações de combustão altamente exotérmicas, (Ilustradas acima ), cujo calor liberado dá inicio a um processo denominado retroalimentação térmica. Tal mecanismo sustenta os processos de pirólise e ignição enquanto houver material combustível disponível. Nesta etapa o fogo se propaga através da superfície do material atingindo outras regiões e tornando o processo da queima absolutamente irreversível. O principal fator que afeta esta etapa é o calor de combustão dos componentes do material polimérico.

\section{Etapa V: Extinção}

$\mathrm{Na}$ medida em que o fogo vai se alastrando por todas as regiões do corpo polimérico, as quantidades de material combustível e de oxigênio (caso o sistema seja fechado) vão diminuindo até um ponto em que o calor gerado pelas reações de combustão não é mais suficiente para sustentar o mecanismo de retroalimentação térmica. O processo da queima entra então no seu estágio de extinção.

O principal fator que afeta esta etapa é o índice de oxigênio do material polimérico.

\section{Modos de se reduzir a inflamabilidade ${ }^{[1-5]}$}

As diversas maneiras de se reduzir a inflamabilidade dos polímeros podem ser agrupadas de modo geral nas seguintes categorias:

- Uso de agentes retardantes de chama reativos, (modificação química dos polímeros);

- Uso de agentes retardantes de chama aditivos;

- Aplicação de revestimentos antichama;

- Combinação de vários métodos.

Podemos dizer que não existe uma técnica que se aplique universalmente a todos os polímeros, em qualquer situação. Em vez disto, cada sistema polimérico poderá exigir soluções diferentes, dependendo dos requisitos particulares quanto à prevenção de incêndio de cada situação.

A modificação química de polímeros é bastante utilizada nos dias de hoje. Ela consiste na introdução de determinados grupamentos químico, (denominados Retardantes de Chama Reativos), diretamente nas macromoléculas durante a síntese das mesmas . Esta técnica apresenta vantagens quanto à estabilidade dos sistemas poliméricos resultantes, uma vez que a incorporação química dos grupamentos retardantes de chama nas cadeias poliméricas os previne de serem eliminados, tornando sua ação mais consistente e duradoura.

O uso dos chamados aditivos retardantes de chama consiste na incorporação física de determinadas substâncias, durante a etapa de processamento dos polímeros. Esta técnica tem a vantagem de não ser diretamente ligada ao processo de manufatura dos polímeros, fator que aumenta consideravelmente o leque de possibilidades na busca de novos materiais. Em relação à técnica da modificação química, o uso de retardantes do tipo aditivo também apresenta vantagens com relação aos custos de matéria-prima e de incorporação. Por todos estes motivos esta é hoje a técnica mais utilizada.

Os revestimentos antichama encontram aplicação na produção de artigos tais como: tintas, correias transportadoras, derivados de madeira e outros, porém tal técnica não apresenta a mesma eficiência das técnicas anteriores.

Abordaremos mais profundamente neste trabalho, apenas o uso de retardantes de chama aditivos, por ser a mais utilizada.

\section{Aditivos retardantes de Chama : Modos de Ação}

Um retardante de chama deve inibir ou suprimir o processo de combustão.

Dependendo de sua natureza, um retardante de chama pode atuar fisicamente, quimicamente, ou de ambas as formas nas fases sólida, líquida ou gasosa; Interferindo com uma etapa particular do processo de queima. 
Discutiremos a seguir, os diversos modos pelos quais um agente retardante de chama pode atuar.

\section{A) Ação física}

São os seguintes os modos pelos quais o processo de combustão pode ser retardado por ação física :

- Por resfriamento :- processos endotérmicos, disparados pelo agente retardante de chama, resfriam o substrato a temperaturas abaixo das requeridas para a ocorrência de pirólise;

- Por formação de camada protetora:- a fase condensada do substrato combustível é isolada da fase gasosa por uma camada protetora sólida ou gasosa. O processo de retroalimentação térmica é retardado ou interrompido, o que causa resfriamento da fase condensada, inibindo a pirólise. A camada protetora também reduz ou impede a transferência de gases combustíveis para a região de queima gasosa, o que contribui para a inibição das reações de combustão;

- Por diluição :-A incorporação de aditivos que liberam gases inertes quando decompostos, dilui os combustíveis nas fases sólida e gasosa, de modo que o ponto de fulgor do material se torna mais elevado.

\section{B) Ação química}

As reações químicas mais significativas que interferem no processo de combustão ocorrem nas fases sólida e gasosa, da seguinte maneira:

- Reações de fase gasosa :- O retardante de chama interrompe a ação dos radicais livres no processo da combustão. Os fenômenos exotérmicos são assim interrompidos, causando o resfriamento do sistema como um todo, o que diminui a evolução de gases inflamáveis até eventualmente a completa extinção.

- Reações de fase sólida :- Dois tipos de reações podem ocorrer na fase sólida: em primeiro lugar, o retardante de chama pode acelerar o processo de fragmentação do polímero, causando um fluxo pronunciado dos fragmentos para fora da esfera de influência da chama, que por falta de combustível, se reduz ou é extinta; em segundo lugar, o retardante de chama pode causar a formação de uma camada de carbono na superfície do polímero, a qual atuará fisicamente como uma camada protetora. Isto pode ocorrer por exemplo, pela ação desidratante do agente sobre o polímero, gerando ligações duplas, as quais podem provocar a carbonização da superfície através de ligações cruzadas e ciclização.

\section{C) Efeitos sinérgicos}

A combinação de retardantes com diferentes modos de ação pode produzir efeitos complementares, sinérgicos ou antagônicos. Enquanto o efeito complementar é a soma das ações individuais, os outros efeitos são maiores e menores respectivamente que a soma de suas ações isoladas. Os efeitos sinérgicos são de grande importância prática. É comum o fato de certo retardante de chama ter pouco ou nenhum efeito quando usado isoladamente mas reduzir significativamente a quantidade necessária de outro retardante, usualmente mais caro, quando ambos são usados em conjunto .

Um caso típico de sinergia é o uso de retardantes de chama halogenados juntamente com trióxido de antimônio, que será discutido mais a frente .

\section{Principais Retardantes de Chama ${ }^{[1,2,5]}$}

São os seguintes, os aditivos retardantes de chama mais utilizados :

- Hidróxido de Alumínio, Boratos, Fosfatos, Halogenados, Trióxido de Antimônio, Hidróxido de Magnésio.

\section{A) Hidróxido de Alumínio, $\mathrm{Al}(\mathrm{OH})_{3}$ ou Alumina Tri Hidratada, (ATH)}

Quando em processo de aquecimento, um composto polimérico que contém o hidróxido atinge temperaturas da ordem de $230{ }^{\circ} \mathrm{C}$, tem início a seguinte reação de desidratação:

$$
2 \mathrm{Al}(\mathrm{OH})_{3}+280 \mathrm{cal} / \mathrm{g} \longrightarrow \mathrm{Al}_{2} \mathrm{O}_{3}+3 \mathrm{H}_{2} \mathrm{O}
$$

A taxa de decomposição máxima ocorre entre 300 e $350^{\circ} \mathrm{C}$, intervalo que coincide com as temperaturas de pirólise da maior parte dos polímeros de uso comum (vide Tabela 1).

Além disso, a cinética desta reação é de tal modo favorável, que o fluxo de calor retirado do substrato atinge a mesma ordem de magnitude do fluxo de calor observado entre as zonas de queima gasosa e de pirólise para boa parte dos polímeros de uso comum. Estima-se por exemplo, em cerca de $700 \mathrm{cal} / \mathrm{min}$, o fluxo de calor entre as zonas de combustão e pirólise para o Polietileno 
sendo queimado em condições estacionárias a uma temperatura superficial de $625^{\circ} \mathrm{C}{ }^{[5]}$. Portanto, durante sua decomposição térmica, o hidróxido de alumínio absorve parte do calor de combustão que retorna para o substrato, oriundo da zona de queima gasosa, atenuando desta maneira o fenômeno da retroalimentação térmica. Assim a superfície do substrato é resfriada, e consequentemente, ocorre redução da taxas de aquecimento e pirólise. Embora o mecanismo de absorção sacrificial de calor seja reconhecidamente o principal modo de atuação do ATH como retardante de chama, os seguintes outros mecanismos também apresentam contribuição significativa:

- O grande volume de água liberada, $(36 \% \mathrm{em}$ massa, cerca de $800 \mathrm{ml} / \mathrm{g}$ a $230^{\circ} \mathrm{C}$ ), faz com que expressivas quantidades adicionais de calor sejam absorvidas tanto para o aquecimento, devido ao elevado calor específico da água, quanto para a vaporização, devido ao elevado calor de vaporização da mesma;

- $\mathrm{O}$ conhecido óxido refratário $\mathrm{Al}_{2} \mathrm{O}_{3}$, que se forma na superfície do substrato, atua como uma camada protetora, isolante térmica, reduzindo ainda mais a troca de calor entre a zona de queima gasosa e a superfície do polímero;

- O vapor d'água liberado tem um efeito diluidor na fase gasosa, reduzindo a quantidade de oxigênio disponível nas vizinhanças da fase condensada e na zona de queima gasosa;

A ação combinada destes processos resulta em basicamente duas formas de atuação, com impacto direto sobre o curso da queima:

- Retirada de calor, inibindo as etapas de aquecimento e pirólise;

- Retirada de Oxigênio, inibindo as reações de pirólise e ignição.

\section{B) Boratos}

Os boratos são usados especialmente como auxiliares de outros retardantes de chama, devido a seu efeito sinérgico. Possuem baixa eficiência quando usados isoladamente .

As formas de uso mais comuns são o pentahidrato, o decahidrato, o ácido bórico e o borato de zinco .

Durante a etapa de aquecimento, estes compostos fundem-se, formando uma camada de borax sobre o substrato, que isola a zona de pirólise da zona de queima gasosa, inibindo o mecanismo da retroalimentação térmica.
Como agentes sinérgicos, os compostos de boro são menos efetivos que o trióxido de antimônio, mas são muito mais baratos, de modo que podem substituir o trióxido totalmente ou em parte, nas combinações com retardantes halogenados.

O tipo de composto de boro a ser usado depende do sistema polimérico em questão. Por exemplo, boratos solúveis como o borato de sódio e o ácido bórico são muito usados para tratamento de artigos confeccionados com celulose, algodão e fibra de madeira por serem solúveis em algum solvente utilizado em etapas intermediárias do processo. Em PVC rígido, o borato de zinco pode ser usado como substituto total ou parcial do trióxido de antimônio. Quando o borato de zinco é usado em conjunto com ATH em PVC, há uma sinergia altamente positiva tanto na retardância de chama quanto na emissão de fumaça.

\section{C) Fosfatos}

No estágio de aquecimento dos compostos atingese uma temperatura na qual os fosfatos sofrem decomposição, gerando ácido fosfórico, que desidrata o substrato polimérico formando uma camada protetora incombustível, inibindo o mecanismo de retroalimentação térmica de modo análogo aos boratos. A desidratação libera também apreciáveis quantidades de água e gases não combustíveis, que colaboram para o efeito final de retardância de chama.

As formas de uso mais comuns são o fosfato de tricloroetila e o polifosfato de amônio .

Há evidências de que os agentes fosforados também atuam na fase gasosa através da espécie HPO, oriunda da decomposição térmica do ácido fosfórico.

O HPO cataliza a recombinação dos radicais $\mathrm{H}^{\text {. }}$ em hidrogênio, reduzindo a energia da chama.

\section{D) Halogenados}

São compostos carbohalogenados de fórmula geral $R X$, onde $R$ é um radical orgânico e $X$ um halogênio, que interferem no mecanismo de radicais livres em fase gasosa que dá origem ao processo de combustão.

Os radicais de alta energia $\mathrm{HO}$ e $\mathrm{H} \cdot$ formados nas etapas iniciais de combustão são neutralizados pelo composto carbohalogenado, através do seguinte mecanismo:

- Inicialmente ocorre a dissociação do agente halogenado: 


$$
\mathrm{RX} \stackrel{\text { calor }}{\longrightarrow} \mathrm{R} \cdot+\mathrm{X} \cdot
$$

- O radical halogenado reage então com uma ligação $\mathrm{C}-\mathrm{H}$, para formar o ácido halogenídrico correspondente:

$$
\mathrm{X} \cdot+\mathrm{RH} \longrightarrow \mathrm{R} \cdot+\mathrm{HX}
$$

- O ácido formado reage com os radicais de alta energia, estabilizando-os e interrompendo o mecanismo de que sustenta o processo de combustão:

$$
\begin{aligned}
& \mathrm{HX}+\mathrm{H} \longrightarrow \mathrm{H}_{2}+\mathrm{X} \text { 。 } \\
& \mathrm{HX}+\mathrm{HO} \longrightarrow \mathrm{H}_{2} \mathrm{O}+\mathrm{X} 。
\end{aligned}
$$

- Os radicais de alta energia $\mathrm{H} \cdot$ e HO são portanto substituidos pelos radicais halogenídricos de baixa energia $X$, incapazes de manter as reações de combustão.

$\mathrm{O}$ verdadeiro efeito retardante de chama é pois exercido pelo ácido halogenídrico.

- Posteriormente, o ácido é regenerado pela reação do radical halogenídrico com uma ligação C-H:

$$
\mathrm{X}^{\circ}+\mathrm{RH} \longrightarrow \mathrm{R}^{\circ}+\mathrm{HX}
$$

Assim, podemos dizer que o ácido halogenídrico atua como um catalisador, não sendo de fato consumido no decorrer do processo.

A efetividade dos retardantes de chama halogenados, teóricamente, deveria aumentar na sequência:

$$
\mathrm{F}<\mathrm{Cl}<\mathrm{Br}<\mathrm{I}
$$

$\mathrm{Na}$ realidade, os agentes fluorados e os iodados não apresentam qualquer efeito retardante de chama. Os fluorados devido ao fato da ligação R-F ser tão forte, que ela não se dissocia para dar origem aos radicais $\mathrm{F}$, não permitindo desta forma o estabelecimento do mecanismo de retardância de chama. Por outro lado, os agentes iodados, ao se decomporem, geram radicais I, de tão baixa energia, que não são capazes de roubar o próton de uma ligação $\mathrm{C}-\mathrm{H}$, para gerar o ácido iodídrico, o que também não permite o estabelecimento do mecanismo de retardância de chama.

Dos dois halogênios restantes, o Bromo é o mais efetivo, porque ele apresenta o balanço mais adequado entre a facilidade de formar o radical livre $\mathrm{X} \cdot$ e a habilidade deste, de gerar o ácido halogenídrico correspondente.
Um aspecto cada vez mais relevante do uso de retardantes de chama halogenados está relacionado com os dois principais compostos gerados pelo seu mecanismo de atuação:

- Os compostos organohalogenados e os ácidos halogenídricos .

Em primeiro lugar, as substâncias organohalogenadas, particularmente as organocloradas e as organobromadas são bem conhecidas pela sua toxidez. Por exemplo, compostos como Tetracloreto de Carbono e Clorofórmio são conhecidos pelo seu potencial carcinogênico .

Em segundo lugar, os ácidos halogenídricos além de serem também altamente tóxicos, possuem um apreciável poder de corrosão sobre máquinas e equipamentos.

Desse modo, a queima de polímeros que contenham retardantes de chama halogenados produz uma considerável quantidade de substâncias potencialmente perigosas, que são emitidas junto com a fumaça.

\section{E) Trióxido de Antimônio}

$\mathrm{O}$ óxido de antimônio $\mathrm{Sb}_{2} \mathrm{O}_{3}$ é praticamente o único composto de antimônio usado como retardante de chama, não apresentando quase nenhuma eficiência, quando usado isoladamente. Entretanto, quando ele é utilizado em conjunto com retardantes de chama halogenados, observa-se uma poderosa sinergia positiva.

Até o momento, não se ofereceu nenhuma interpretação teórica satisfatória sobre o modo de ação do $\mathrm{Sb}_{2} \mathrm{O}_{3}$. Acredita-se contudo que sua ação também se dê sobre o mecanismo de radicais livres que propicia a combustão.

De acordo com algumas teorias, em temperaturas acima de $250^{\circ} \mathrm{C}$, o trióxido de antimônio reagiria com os ácidos halogenídricos para formar o halogeneto correspondente, $\mathrm{SbX}_{3}$, o qual por ser um poderoso ácido de Lewis, atuaria como interceptador de radicais livres, de forma mais eficiente que os ácidos halogenídricos.

Alguns autores sugerem que o antimônio trivalente cataliza a formação dos radicais livres halogenados. Outros sugerem ainda, que o $\mathrm{SbX}_{3}$ retarda a velocidade de escape dos mesmos, aumentando desta forma seu tempo de permanência na zona de reações gasosas o que incrementa a inibição do processo de queima.

Há relatos na literatura científica de pesquisas que associam a exposição a elevados níveis de pó de $\mathrm{Sb}_{2} \mathrm{O}_{3}$ com câncer no pulmão . 
Outros trabalhos relatam que o $\mathrm{Sb}_{2} \mathrm{O}_{3}$ tem efeito deletério sobre a pigmentação e as propriedades físicas dos polímeros, além de aumentar substancialmente a emissão de fumaça e de acelerar os processos de degradação.

\section{F) Hidróxido de Magnésio}

Este composto tem um efeito de retardância de chama similar ao do $\mathrm{Al}(\mathrm{OH})_{3}$, mas apresenta temperatura de decomposição mais elevada, $\left(300^{\circ} \mathrm{C}\right)$. Por apresentar custo elevado é usado normalmente, apenas nos polímeros que apresentam temperaturas de processamento acima da temperatura de decomposição térmica do ATH.

\section{Compromisso: Retardância de Chama versus Emissão de Fumaça ${ }^{[1]}$}

Os retardantes de chama que agem quimicamente interrompem a ação dos radicais livres, porque reagem com eles gerando outras substâncias menos energéticas, que são incapazes de desencadear as reações de combustão. Porquanto, tais agentes inibem apenas a etapa da ignição, sem afetar os processos de pirólise, que continuam a gerar gases tóxicos e fuligem enquanto houver calor suficiente disponível. Consequentemente, a utilização de retardantes de chama quimicamente ativos resulta invariavelmente no efeito colateral de aumento na emissão de fumaça e gases tóxicos. Este é por exemplo, o caso dos retardantes de chama halogenados, principalmente quando utilizados em conjunto com trióxido de antimônio.

A utilização de retardantes de chama de ação física, como os hidróxido de alumínio e de magnésio e alguns compostos de boro e fósforo, não provoca o referido efeito colateral pelo fato de tais agentes atuarem primariamente na redução das taxas de pirólise, interrompendo desta forma o processo de geração do fogo, simultaneamente aos processos de geração de fuligem e de substâncias voláteis tóxicas ou inflamáveis.

Por outro lado, verifica-se que exatamente por atuarem diretamente sobre o mecanismo de radicais livres, que sustenta a combustão, os retardantes de chama de ação química são mais eficientes em reduzir a inflamabilidade dos materiais, podendo ser dosados em quantidades que normalmente não prejudicam as propriedades mecânicas e elétricas dos polímeros, fatores que muitas vezes são comprometidos pelo uso de retardantes de chama de ação física, devido à ne- cessidade de se utilizar altas dosagens destes últimos para obter o efeito antichama desejado.

\section{Emissão de Fumaça : Efeitos e Técnica de Medição[1-3]}

Os efeitos da fumaça são particularmente graves no caso de aplicações de materiais poliméricos em recintos fechados, tais como: Residências, escolas, centros comerciais, hoteis, prédios de apartamento, plataformas de petróleo, ônibus, metrô, navios, aviões, etc.

São basicamente quatro os efeitos deletérios da fumaça sobre os seres humanos:

- Perda de orientação por obscurecimento e lacrimogênese;

- Toxidez dos gases emitidos $(\mathrm{CO}, \mathrm{HCl}, \mathrm{HBr}$, $\mathrm{HCN}, \mathrm{NO}_{\mathrm{X}}$, Organohalogenados, etc);

- Sufocação, por diluição do oxigênio;

- Pânico, gerado por combinação dos fatores acima.

Em adição aos efeitos danosos da fumaça sobre os seres humanos, há também consequências altamente indesejáveis sobre instalações e equipamentos devidas a seus componentes corrosivos.

Os efeitos de toxidez e corrosão de fumaça são normalmente medidos por testes específicos e também se constituem em parâmetros essenciais na avaliação do potencial de risco dos materiais em condições de incêndio. Contudo, apesar de sua grande relevância, tais metodologias não serão abordadas neste trabalho devido a natureza preliminar do mesmo.

A emissão de fumaça pode ser medida por métodos gravimétricos ou por métodos ópticos. Os primeiros se baseiam na determinação da massa das partículas de fumaça depositadas sobre um filtro sob condições padronizadas enquanto que os últimos envolvem medidas da fração de luz absorvida ou obstruída pela fumaça (obscurecimento). Os métodos ópticos são os mais utilizados justamente por estarem mais relacionados com um dos aspectos práticos de segurança em condições de incêndio: A capacidade das pessoas identificarem saídas de emergência através de sinais luminosos e a capacidade dos bombeiros entrarem nos recintos para darem ataque ao fogo.

O método ASTM E662 é um dos mais utilizados e se baseia numa câmara completamente fechada (Figura 2) de 914 por 610 por $914 \mathrm{~mm}$, na qual um corpo de prova de $76,2 \mathrm{~mm}^{2}$ é fixado verticalmente num suporte de tal modo que uma área de $65,1 \mathrm{~mm}^{2}$ possa ser exposta ao calor de duas formas distintas: Em condições de chama, sob a ação de queimadores ou na 


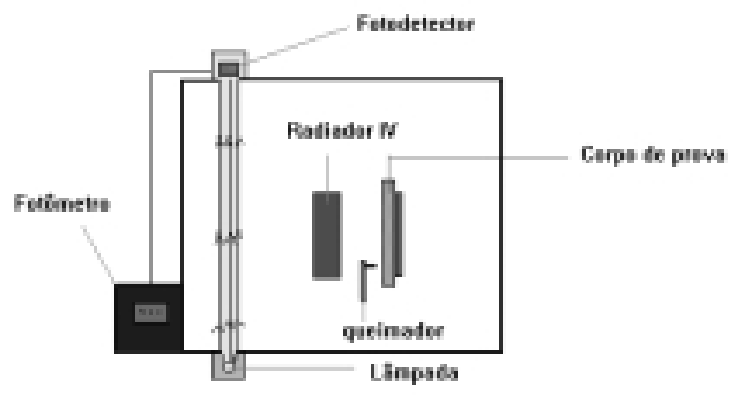

Figura 2. Vista da câmara ASTM E662

ausência de chama sob a ação de uma resistência radiante . A fonte de calor em ambas as condições é ajustada para fornecer um fluxo de $2,5 \mathrm{~W} / \mathrm{cm}^{2}$ na superfície exposta do corpo de prova. Um fotômetro de caminho óptico vertical é utilizado para minimizar erros devido à extratificação da fumaça.

A emissão de fumaça é medida por uma grandeza denominada densidade de fumaça (Ds), dada pela equação abaixo:

Ds $=132$ LOG $(100 / \mathrm{T})$

Onde 132 é uma constante determinada pela geometría da câmara e $\mathrm{T}$ é a transmitância do feixe de luz, medida diretamente no fotômetro.

Os seguintes dois parâmetros permitem sintetizar os resultados do ensaio, sendo suficientes para caracterizar precisamente o comportamento do material polimérico:

$D m$ : definida como a máxima densidade de fumaça emitida durante o teste;

Tm: definido como o tempo necessário para se atingir Dm.

Medidas são feitas em duas condições: Na presença e na ausência de chama, sendo a segunda situação mais crítica quanto à emissão de fumaça durante os incêndios, posto que a fuligem e o monóxido de carbono não são totalmente oxidados, ao contrário do que ocorre na primeira.

\section{Avaliação da Inflamabilidade ${ }^{[1,2]}$}

A avaliação da inflamabilidade dos materiais poliméricos pode em princípio ser feita através de ensaios em larga escala, onde se procura verificar o desempenho dos materiais em situação real de incêndio. Contudo, por serem muito dispendiosos, além de demandarem um tempo grande para a sua execução, tais ensaios se prestam especificamente para homologação de produtos acabados.

Para fins de seleção de materiais com vistas à criação de novos produtos resistentes à chama foram desenvolvidos testes em escala de laboratório, os quais apesar de não fornecerem informações fidedignas a respeito do comportamento dos materiais em condições reais de incêndio, se prestam muito bem para finalidade de comparação do desempenho de diferentes materiais ou de diferentes formulações do mesmo polímero principal.

Cita-se nas tabelas de 5 a 11, alguns dos principais tipos de ensaios que têm sido desenvolvidos e padronizados para avaliação da inflamabilidade de polímeros. Cada um dos testes citados permite avaliar um determinado aspecto do processo da queima, dando ênfase a uma de suas etapas descritas anteriormente neste trabalho, sendo portanto necessária a realização de vários ensaios para que se possa ter uma abordagem completa da inflamabilidade dos materiais.

Os testes de inflamabilidade podem ser classificados nas seguintes categorias $^{[3]}$ :

- Que medem a facilidade de ignição dos polímeros;

- Que medem quão rápido o fogo se espalha pela superfície do polímero;

- Que medem quão rápido o fogo penetra uma parede ou barreira;

- Que medem quão intensa e rápida é a liberação de calor pelos materiais poliméricos;

- Que medem a facilidade com que o fogo se extingue; Descreveremos abaixo dois dos testes mais importantes, que são feitos nos materiais moldados em corpos de prova .

\section{Índice de Oxigênio}

O Índice de oxigênio é uma medida da facilidade com que os materiais poliméricos sofrem ignição. Sendo que o processo da queima envolve várias outras etapas, podemos dizer que o Índice de Oxigênio é uma medida parcial da inflamabilidade dos polímeros. Ele mede na verdade a capacidade do material sofrer ignição na condição limite de escassez de oxigênio. Por este motivo, é as vezes chamado de Índice Limite de Oxigênio e quanto menor seu valor, maior a facilidade com que os materiais sofrem ignição.

O Índice de Oxigênio está relacionado com a capacidade dos materiais de gerar os radicais livres de alta energía $\mathrm{H} \cdot$ e $\mathrm{HO}$, que darão início à etapa de ignição. Deste modo, ele é grandemente afetado pela temperatura ambiente, se deslocando para valores cada vez menores na medida em que 


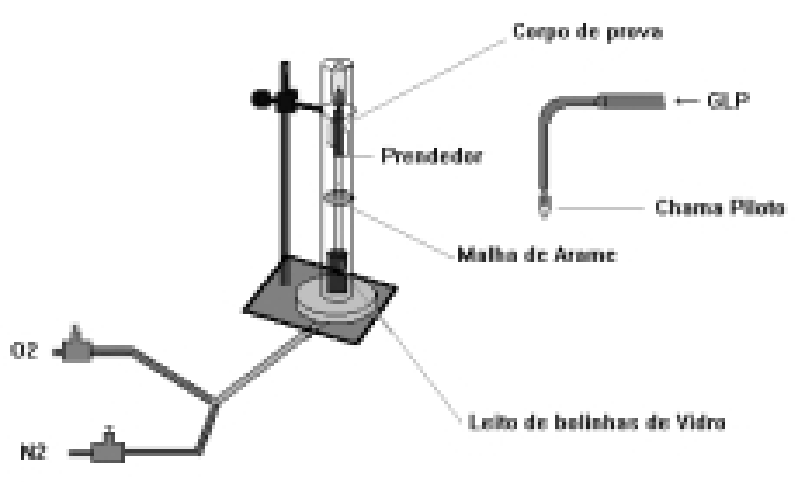

Figura 3. Aparelho para medição do Índice de Oxigênio, ( ASTM D2863)

o ambiente se aquece. Por este motivo, existem aparelhos comerciais que apresentam a versatilidade de permitir a execução do ensaio em diferentes temperaturas.

O Índice de Oxigênio é medido conforme o procedimento padrão ASTM D2863, utilizando-se o equipamento ilustrado na figura 3.

Inicialmente procede-se ensaios exploratórios, testando várias concentrações de $\mathrm{O}_{2}$ na mistura $\mathrm{O}_{2}$ / $\mathrm{N}_{2}$ até se encontrar uma concentração, na qual o material sendo testado, queima a uma taxa lenta e uniforme após ser submetido à chama piloto.

Então se procede a testes adicionais, reduzindose gradativamente a concentração de $\mathrm{O}_{2}$, até o ponto em que a queima seja sustentada por não mais que três minutos ou, em caso de materiais muito inflamáveis, até que $50 \%$ do corpo de prova tenha sido queimado. Neste ponto, $0,25 \%$ de redução na concentração de oxigênio deve provocar extinção da chama.

A concentração de oxigênio, necessária para se atingir a referida situação é designada como o Índice de Oxigênio do material.

Os corpos de prova são recortados de chapas produzidas por prensagem a quente e devem ter as seguintes dimensões:

$150 \mathrm{~mm}$ de comprimento;

$6 \mathrm{~mm}$ de largura;

$3 \mathrm{~mm}$ de espessura.

A fim de evitar influência da umidade atmosférica, os corpos de prova devem ser previamente condicionados em um dessecador com sílica gel por $24 \mathrm{~h}$.

A norma ABNT EB 1124 fixa um Índice de Oxigênio mínimo de $30 \%$ para o isolamento de cabos elétricos de baixa tensão, confeccionados com PVC .

São dados na Tabela 3, os valores de índice de oxigênio de alguns polímeros de uso comercial .
Tabela 3. Índice de oxigênio de alguns polímeros ${ }^{[3]}$

\begin{tabular}{lclc}
\hline \multicolumn{1}{c}{ Polímero } & $\begin{array}{l}\text { Índice de } \\
\text { Oxigênio }\end{array}$ & \multicolumn{1}{c}{ Polímero } & $\begin{array}{c}\text { Índice de } \\
\text { Oxigênio }\end{array}$ \\
\hline $\begin{array}{l}\text { Polietileno } \\
\text { (Allied 1220) }\end{array}$ & 17 & Algodão & 19 \\
Polipropileno & 18 & $\begin{array}{l}\text { Poliacrilonitrila } \\
\text { (Plexiglas) }\end{array}$ & 17 \\
$\begin{array}{l}\text { Hercules (Profax } \\
\text { PC072) }\end{array}$ & & $\begin{array}{l}\text { Nylon 6-6 (BASF } \\
\text { AK3) }\end{array}$ & 25 \\
$\begin{array}{l}\text { Poliestireno } \\
\text { (Koppers 8) }\end{array}$ & 18 & $\begin{array}{l}\text { Epoxi (Araldite } \\
\text { 6005 / TONOX) }\end{array}$ & 27 \\
$\begin{array}{l}\text { Poli(cloreto de } \\
\text { vinila) Union }\end{array}$ & 40 & $\begin{array}{l}\text { Acetato de } \\
\text { celulose }\end{array}$ & 19 \\
$\begin{array}{l}\text { Carbide QSAH-7) } \\
\text { Poli(tetraflúor-eti- }\end{array}$ & & \\
$\begin{array}{l}\text { leno (Du Pont } \\
\text { Teflon 6) }\end{array}$ & 95 & \\
\hline
\end{tabular}

\section{Técnica da Queima Vertical[1]}

Este teste avalia a capacidade do material de propagar a chama na mesma direção em que se propagam os produtos de pirólise, a direção vertical. Por este motivo, este é um teste bastante rigoroso pois as condições de queima são propositalmente favoráveis.

Como todos os demais métodos de avaliação da inflamabilidade dos materiais, o teste da queima vertical se presta para comparar dois materiais nas suas estritas condições empíricas, não havendo qualquer correlação com condições reais de incêndio.

As condições do ensaio estão normalizadas numa publicação denominada UL 94, da Underwriters Laboratories, entidade privada norteamericana responsável pela normalização de produtos de uso doméstico nos EUA.

A norma contém na verdade vários testes de inflamabilidade para materiais poliméricos, além do teste da queima vertical.

O teste da queima vertical tem sido usado internacionalmente para caracterizar a inflamabilidade de compostos políméricos empregados na confecção de produtos elétricos de uso doméstico, tais como máquinas de costura, carcaças de aparelhos de TV e de computadores, fornos de microondas, etc...

O ensaio é executado em corpos de prova, recortados de chapas produzidas por prensagem a quente ou injetados diretamente em moldes adequados, de modo a apresentarem as seguintes dimensões:

Comprimento $=(125 \pm 5) \mathrm{mm}$;

Largura $=(13,0 \pm 0,3) \mathrm{mm}$;

Espessura $<13 \mathrm{~mm}$. 
Após a operação de corte, deve-se tormar cuidado especial na eliminação de pó e de quaisquer outros resíduos retidos na superfície. As arestas devem ser cuidadosamente lixadas e os raios das quinas, acertados para não excederem a $1,3 \mathrm{~mm}$.

Os ensaios devem ser realizados numa sala com temperatura e umidade relativa controladas respectivamente em $(23 \pm 2){ }^{\circ} \mathrm{C}$ e $(50 \pm 5) \%$, devendo os corpos de prova serem acondicionados nesta sala por no mínimo $48 \mathrm{~h}$ antes do teste.

É o seguinte o procedimento do ensaio:

- A chama é colocada sob a extremidade do corpo de prova, conforme ilustrado na figura 4 , onde é mantida por 10 segundos, após o que é retirada;

- Quando o corpo de prova para de queimar, a chama é de novo colocada sob o mesmo por mais 10 segundos, após o que é novamente retirada;

- As seguintes obsevações devem ser anotadas: t1 = Duração da chama no corpo de prova, após a primeira aplicação;

t2 = Duração da chama no corpo de prova, após a segunda aplicação;

t3 = Duração da chama mais a incandescência, após a segunda aplicação;

Se o corpo de prova queima até o prendedor; Se o corpo de prova emite gotas ou fagulhas que incendeiam o algodão .

- Executa-se ensaios em 5 corpos de prova e então, aplica-se os critérios da tabela 4 para classificação do material .

- Um novo conjunto de cinco corpos de prova deverá ser ensaiado, caso ocorram as seguintes situações:

- Apenas um dos cinco corpos de prova não se encaixou em uma dada classificação;

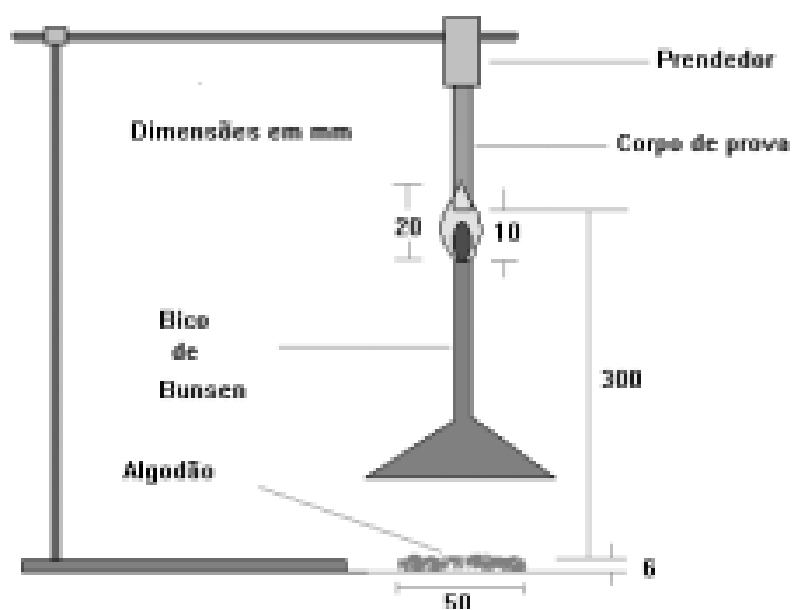

Figura 4. Equipamento para o ensaio de queima vertical, ( Segundo a norma UL 94 )
Tabela 4. Critérios de avaliação do teste de queima vertical da norma UL94

\begin{tabular}{|c|c|c|c|}
\hline Critérios & Vo & V1 & $\mathbf{V 2}$ \\
\hline $\begin{array}{l}\text { Valores individuais de } \mathrm{t} 1 \text { e } \mathrm{t} 2 \\
\text { para os } 5 \text { C.P. }\end{array}$ & $<10$ s & $<30$ s & $<30$ s \\
\hline $\begin{array}{l}\text { Somatória de }(\mathrm{t} 1+\mathrm{t} 2) \text { para os } 5 \\
\text { C.P. }\end{array}$ & $<50$ s & $<250$ s & $<250$ s \\
\hline Valores individuais de $\mathrm{t} 3$ & $<30$ s & $<60$ s & $<60$ s \\
\hline $\begin{array}{l}\text { Queima com chama ou in- } \\
\text { candescência até o prendedor }\end{array}$ & Não & Não & Não \\
\hline $\begin{array}{l}\text { Queima do algodão por gotas } \\
\text { ou fagulhas emitidas }\end{array}$ & Não & Não & Sim \\
\hline
\end{tabular}

- O tempo total de chama, (Somatória de $\mathrm{t} 1+\mathrm{t} 2$ para os 5 C.P. ), cair no intervalo $(51$ - 55$) \mathrm{s}$ para V0 ou no intervalo ( 251 - 255 ) s para V.

- Todos os corpos de prova do segundo grupo devem satisfazer os critérios da tabela 4 para que a classificação seja feita.

\section{Normas Internacionais $[6,7]$}

No âmbito da padronização e regulamentação de metodologias de avaliação de produtos quanto à prevenção de incêndio, destaque deve ser dado ao Código de Regulamentações Federais dos EUA, que por exemplo, em seu capítulo 16, partes de 1602 a 1632, apresenta 11 normas, que regulamentam o uso de fibras sintéticas em produtos de uso comercial compreendendo desde definições acerca da responsabilidade sobre fiscalização e interpretação (norma 1602), passando por metodologias de avaliação de roupas de dormir para crianças (norma 1616), até uma norma específica para avaliação da inflamabilidade de colchões pela ação de tocos de cigarros ( norma 1632 ).

A determinação do risco de fogo por classificação ocupacional é uma característica bem estabelecida de muitos códigos de edificações. Tais códigos controlam o uso de materiais de construção e de sistemas de segurança em estruturas baseadas na necessidade relativa de desempenho quanto à prevenção de incêndios entre as diferentes ocupações.

Os materiais constituintes do mobiliário, dos acessórios e dos equipamentos contidos nas edificações podem entretanto representar riscos suplementares àqueles delimitados pelo escopo dos citados códigos, a menos que sejam consistentes com 
a natureza das ocupações do ponto de vista da prevenção de incêndio.

A norma ASTM E931-85 descreve um procedimento padrão para se determinar o potencial de risco em edificações com respeito à suas naturezas ocupacionais de modo a prover uma base lógica para o estabelecimento de níveis aceitáveis de desempenho em condições de incêndio para mobiliários, acessórios e equipamentos nelas contidos.

São apresentadas no capítulo 7.1, as principais normas ASTM, relevantes para o desempenho de materiais poliméricos com relação ao fogo .

São apresentados no capítulo 7.2, as normas UL, voltadas para homologação do uso de materiais poliméricos, com vistas à segurança dos mesmos para uso pelos consumidores.

No capítulo 7.3, apresenta-se as normas NFPA, voltadas específicamente para prevenção de incêndio com o uso de materiais poliméricos .

No capítulo 7.4, são listadas as normas UBC, destinadas à padronização do uso de materiais de construção com vistas à prevenção de incêndio.

Os níveis aceitáveis de desempenho, tanto para materiais de contrução, quanto para os materiais que constituem o conteúdo das edificações, devem ser estabelecidos levando-se em consideração todos os fatores relevantes quanto à prevenção de incêndio citados nos capítulos anteriores e não apenas um de seus aspectos isolados. As normas ISO, mostradas no capítulo 7.5 abaixo merecem destaque, justamente por considerarem tais fatores. As normas ISO são convenientemente classsificadas em: - Materiais de contrução (Tabela 9), Produtos eletrotécnicos (Tabela 10) e Materiais Poliméricos (Tabela 11).

É interessante observar que uma mesma norma base, é reeditada pelas diferentes entidades, gerando famílias de normas similares. Dentro de cada família, há pequenas variações, dependendo do foco dado pela instituição.

É fornecida abaixo uma lista das normas internacionais, relevantes quanto à segurança no uso de polímeros em condições de incêndio.

\section{ASTM "American Society for testing and Materials"}

Tabela 5. Normas ASTM relevantes ao comportamento dos polímeros em condições de incendio.

\begin{tabular}{|c|c|c|c|}
\hline Norma & Produto Alvo & Norma & Produto Alvo \\
\hline C 209 & Placas de isolamento & D 470 & Isolação elétrica com termofixos \\
\hline C 542 & Gaxetas de vedação & D 876 & Isolação elétrica emflexíveis de PVC \\
\hline C 864 & Juntas e coxins & D 1000 & Isolação elétrica de fitas adesivas \\
\hline D 92 & Ignição de líquidos, vaso aberto & D 1230 & Fibras texteis \\
\hline D 93 & Ignição de líquidos, vaso fechado & D 1360 & Tintas e revestimentos \\
\hline D 229 & Isolação elétrica de lâminas rígidas & D 1433 & Plásticos \\
\hline D 350 & Isolação elétrica de luvas flexíveis & D 1692 & Espumas \\
\hline D 378 & Correias planas de borracha & D 1929 & Ignição de plásticos \\
\hline D 461 & Feltros & D 2633 & Isolação elétrica com termoplásticos \\
\hline D 2671 & Tubos termocontráteis & D 3894 & Queima em canto de recinto fechado \\
\hline D 2859 & Pisos sintéticos, teste da pílula & D 4100 & Fumaça por gravimetria \\
\hline D 2863 & Índice de oxigênio & D 4108 & Roupas protetoras, chama aberta \\
\hline D 3675 & Painel radiante de espumas & D 4151 & Mantas e cobertores \\
\hline D 4433 & Papel e papelão & D 4372 & Barracas de acampamento \\
\hline E 69 & Lã tratada & E 800 & Gases gerados durante incêndios \\
\hline E 84 & $\begin{array}{l}\text { Queima superficial de materiais de construção, } \\
\text { Teste do Túnel }\end{array}$ & E 163 & Janelas \\
\hline E 108 & Telhas & Е 286 & Queima superficial - Túnel \\
\hline E 119 & Padrões de queima & E 603 & Queima em cômodos \\
\hline E 152 & Portas & E 648 & Pisos - Painel radiante \\
\hline E 160 & Madeira tratada & E 814 & Portas corta-fogo \\
\hline E 662 & Câmara NBS - Densidade de Fumaça & E 906 & Liberação de calor \\
\hline
\end{tabular}


UL : “ Underwriters Laboratories "

Tabela 6. Normas UL relevantes quanto ao comportamento dos polímeros em condições de incêndio

\begin{tabular}{|c|c|c|c|}
\hline Norma & Produto alvo & Norma & Produto alvo \\
\hline 9 & Janelas, similar à ASTM E 163 & $746 \mathrm{C}$ & Equipamentos elétricos \\
\hline $10 \mathrm{~B}$ & Portas, similar à ASTM E 152 & 790 & Telhas, similar à ASTM E 108 \\
\hline 44 & Fios e Cabos - Isolamento de borracha & 910 & $\begin{array}{l}\text { Cabos elétricos e de fibra ótica } \\
\text { Queima horizontal }\end{array}$ \\
\hline 83 & Fios e Cabos - Isolamento de termofixos & 1056 & Móveis estofados \\
\hline 94 & Componentes de utensílios domésticos & 1479 & Portas corta-fogo \\
\hline 181 & Dutos e conectores de ar & 1581 & $\begin{array}{l}\text { Cabos elétricos e cordas flexíveis } \\
\text { Queima vertical }\end{array}$ \\
\hline 214 & Fibras e filmes & 1666 & $\begin{array}{l}\text { Cabos elétricos de fibra ótica } \\
\text { Queima vertical }\end{array}$ \\
\hline 263 & $\begin{array}{l}\text { Padrões de queima } \\
\text { Similar à ASTM E } 119\end{array}$ & 1685 & $\begin{array}{l}\text { Cabos elétricos e de fibra ótica } \\
\text { Queima vertical e emissão de fumaça }\end{array}$ \\
\hline 651 & Conduítes de PVC & 1709 & Materiais de proteção para estruturas de aço \\
\hline $651 \mathrm{~A}$ & Conduítes de PVC rígido e PEAD & 1820 & $\begin{array}{l}\text { Tubos pneumáticos, } \\
\text { Inflamabilidade e emissão de fumaça }\end{array}$ \\
\hline 723 & $\begin{array}{l}\text { Queima superficial de materiais de } \\
\text { construção, Teste do Túnel } \\
\text { Similar à ASTM E } 84\end{array}$ & 1887 & $\begin{array}{l}\text { Tubos aspersores, } \\
\text { Inflamabilidade e emissão de fumaça }\end{array}$ \\
\hline $746 \mathrm{~A}$ & Ignição de materiais poliméricos & & \\
\hline
\end{tabular}

NFPA "National Fires Protection Association"

Tabela 7. Normas NFPA relevantes ao comportamento dos polímeros em condições de incêndio

\begin{tabular}{|c|c|c|c|}
\hline Norma & Produto alvo & Norma & Produto alvo \\
\hline 251 & $\begin{array}{l}\text { Padrões de queima, } \\
\text { Similar à ASTM E } 119 \text { e à UL } 263\end{array}$ & 259 & $\begin{array}{l}\text { Potencial calorífico, } \\
\text { Calorímetro com bomba de oxigênio }\end{array}$ \\
\hline 252 & $\begin{array}{l}\text { Portas, } \\
\text { Similar à ASTM E } 152 \text { e à UL } 10 \text { B }\end{array}$ & 260 & $\begin{array}{l}\text { Componentes de mobilíarios, } \\
\text { Ignição por tocos de cigarros }\end{array}$ \\
\hline 253 & $\begin{array}{l}\text { Pisos - Painel radiante } \\
\text { Similar à ASTM E } 648\end{array}$ & 261 & $\begin{array}{l}\text { Maquetes de mobilíarios, } \\
\text { Ignição por tocos de cigarro }\end{array}$ \\
\hline 255 & $\begin{array}{l}\text { Queima superficial de materiais de } \\
\text { construção, Teste do Túnel } \\
\text { Similar à ASTM E } 84\end{array}$ & 262 & $\begin{array}{l}\text { Cabos elétricos e de fibra ótica, queima ho- } \\
\text { rizontal } \\
\text { Similar à UL } 910\end{array}$ \\
\hline 256 & $\begin{array}{l}\text { Telhas, } \\
\text { Similar à ASTM E } 108 \text { e à UL } 790\end{array}$ & 263 & $\begin{array}{l}\text { Liberação de calor } \\
\text { Similar à ASTM E } 906\end{array}$ \\
\hline 257 & $\begin{array}{l}\text { Janelas, } \\
\text { Similar à ASTM E } 163 \text { e à UL } 9\end{array}$ & $264 \mathrm{~A}$ & $\begin{array}{l}\text { Móveis estofados e colchões, taxa de libe- } \\
\text { ração de calor, calorímetro cônico NBS }\end{array}$ \\
\hline 258 & $\begin{array}{l}\text { Câmara NBS - Densidade de fumaça } \\
\text { Similar à ASTM E } 662\end{array}$ & 701 & $\begin{array}{l}\text { Fibras e Filmes } \\
\text { Similar à UL } 214\end{array}$ \\
\hline
\end{tabular}


ICBO "International Conference of Building Officials " - UBC "Uniform Building Code "

Tabela 8. Normas UBC relevantes ao comportamento dos polímeros em condições de incêndio

\begin{tabular}{|c|c|c|c|}
\hline Norma & Produto alvo & Norma & Produto alvo \\
\hline $32-7$ & $\begin{array}{l}\text { Telhas, } \\
\text { Similar às normas: } \\
\text { ASTM E 108, UL } 790 \text { e NFPA } 256\end{array}$ & $43-4$ & $\begin{array}{l}\text { Janelas } \\
\text { Similar às normas: } \\
\text { ASTM E } 163 \text { e UL } 9\end{array}$ \\
\hline $42-1$ & $\begin{array}{l}\text { Queima superficial de materiais de } \\
\text { contrução, Teste do Túnel } \\
\text { Similar à ASTM E } 84 \text { e NFPA } 255\end{array}$ & $52-2$ & $\begin{array}{l}\text { Emissão de fumaça pela câmera "Rohm and } \\
\text { Hass" } \\
\text { Similar à ASTM D } 2843\end{array}$ \\
\hline $2-2$ & Coberturas texteis de paredes & $52-3$ & $\begin{array}{l}\text { Ignição de plásticos } \\
\text { Similar à ASTM D } 1929\end{array}$ \\
\hline $43-1$ & $\begin{array}{l}\text { Padrões de Queima } \\
\text { Similar às normas: } \\
\text { ASTM E 119, UL } 263 \text { E NFPA } 251\end{array}$ & $52-4$ & $\begin{array}{l}\text { Plásticos transparentes, } \\
\text { Similar à ASTM D } 635\end{array}$ \\
\hline $43-2$ & $\begin{array}{l}\text { Portas } \\
\text { Similar às normas: } \\
\text { ASTM E 152, UL } 10 \text { B e NFPA } 252\end{array}$ & & \\
\hline
\end{tabular}

ISO "International Standards Organization "

A) Materiais de Construção

Tabela 9. Normas ISO sobre o comportamento ao fogo dos materiais de construção.

\begin{tabular}{|c|c|c|}
\hline Assunto & Referência & Descrição \\
\hline \multirow{4}{*}{ Diretrizes } & DTR 11696 & $\begin{array}{l}\text { Aplica o dos resultados de testes de inflamabilidade para predição } \\
\text { de desempenho em condições de incêndio }\end{array}$ \\
\hline & DTR 11925-1 & Teoria da Ignição \\
\hline & DTR 5658-1 & Teoria da Propagação de Chama \\
\hline & Guia ISO 52 & Terminologia dos Testes de Inflamabilidade \\
\hline \multirow{3}{*}{ Ignição } & ISO 5657 & Teste de Ignição pelo Cone Radiante \\
\hline & CD 11925-2 & Fonte de Chama Simples \\
\hline & CD 11925-3 & Fonte de Chama Múltipla \\
\hline \multirow{2}{*}{ Propagação } & ISO $5658-2$ & Propagação Lateral sobre Superfícies Verticais \\
\hline & CD 5658-3 & Propagação Lateral e Ignição \\
\hline \multirow{2}{*}{ Liberação de Calor } & ISO $5660-1$ & Calorímetro Cônico \\
\hline & WD 5660-3 & Taxa de Queima \\
\hline \multirow{2}{*}{$\begin{array}{l}\text { Obscurecimento por } \\
\text { Fumaça }\end{array}$} & DIS 5924 & Câmera Dual (Método Estático) \\
\hline & WD 5660-2 & Calorímetro Cônico (Método Dinâmico) \\
\hline \multirow{2}{*}{ Teste de Larga Escala } & ISO 9705 & Teste de Queima em Canto de Recinto Fechado \\
\hline & CD 8337 & Teste de Queima em Canto de Recinto Aberto \\
\hline Toxidez & $\begin{array}{l}\text { ISO TR } 9122 \\
\quad(1-5)\end{array}$ & Testes diversos \\
\hline
\end{tabular}




\section{B ) Produtos Eletrotécnicos}

Tabela 10. Normas ISO sobre o comportamento de produtos eletrotécnicos em condições de incêndio

\begin{tabular}{ccl}
\hline Assunto & Referência & \\
\hline Terminologia & IEC 695-4 & Terminologia dos Testes de Queima \\
Ignição & IEC 695-2-1 & Teste do Fio Incandecente \\
& IEC 695-2-2 & Teste Chama Agulhada \\
\hline Diretrizes & IEC 695-1-1 & Guia sobre a periculosidade em incêndios \\
& IEC 695-7-1 & Guia sobre a toxidez em incêndios \\
& IEC 695-7-2 & Seleção de testes de Toxidez \\
& IEC 695-7-3 & Uso e interpretação de testes de toxidez \\
& IEC '89 Sec 70 & Testes de toxidez em escala de laboratório \\
& IEC '89 & Guia sobre efeitos Tóxicos não usuais \\
\hline Liberação de Calor & IEC 695-8-1 & Diretrizes Gerais \\
& IEC 695-8-2 & Seleção de Testes \\
\hline Propagação de Chama & IEC 331 & Integridade dos Circuítos \\
& IEC 332-1 & Queimados de Cabos em escala de laboratório \\
& IEC 332-3 & Arranjo vertical de cabos \\
& IEC 695-8-3 & Diretrizes gerais sobre a propagação de chama \\
& IEC 695-8-4 & Testes de propagação de chama \\
\hline Corrosão por Fumaça & IEC 695-3-1 & Diretrizes gerais \\
& IEC 695-5-1 $695-3-2$ & Método de teste \\
& IEC 695-5-2 & Diretrizes Gerais \\
& Diretrizes sobre a metodologia de ensaio \\
\hline Obscuração por Fumaça &
\end{tabular}

\section{C) Materiais Poliméricos}

Tabela 11. Normas ISO sobre o comportamento dos polímeros em condições de incêndio

\begin{tabular}{|c|c|c|}
\hline Assunto & Referência & Descrição \\
\hline \multirow{4}{*}{ Diretrizes } & TR 10840 & Desenvolvimento e uso de testes de queima \\
\hline & CD 4589-1 & Índice de Oxigênio \\
\hline & DIS 5659-1 & Testes de Obscurecimento por Fumaça \\
\hline & DIS 11907-1 & Testes de Corrosão por Fumaça \\
\hline \multirow{2}{*}{ Ignição } & DIS 871 & Temperatura de Ignição \\
\hline & TR 10353 & Revisão sobre fontes de Ignição \\
\hline \multirow{2}{*}{ Índice de Oxigênio } & ISO 4589-2 & A temperatura Ambiente \\
\hline & DIS 4589-3 & A temperaturas Elevadas \\
\hline \multirow{5}{*}{ Propagação } & ISO 9772 & Espumas Rígidas \\
\hline & ISO 9773 & Filmes \\
\hline & ISO 1210 & Inflamabilidade em pequenos corpos de prova \\
\hline & ISO 10351 & Inflamabilidade com fonte de chama de $125 \mathrm{~mm}$ \\
\hline & DIS 12992 & Queima vertical de Filmes de Folhas \\
\hline Liberação de calor & WI 599 & Calorímetro Simplificado \\
\hline \multirow{2}{*}{$\begin{array}{c}\text { Obscurecimento por } \\
\text { Fumaça }\end{array}$} & ISO 5659-2 & Câmera Simples (Método Estático) \\
\hline & WD 5659-3 & Câmera Dinâmica \\
\hline \multirow{2}{*}{$\begin{array}{l}\text { Corrosividade da } \\
\text { Fumaça }\end{array}$} & DIS 11907-2 & Método Estático \\
\hline & DIS 11907-3 & Método Dinâmico \\
\hline
\end{tabular}




\section{Referências Bibliográficas}

1. Gallo, J. B.; "Uso de Hidróxido de Alumínio tratado superficialmente em fios e cabos elétricos de baixa tensão", Dissertação de mestrado apresentada ao Departamento de Engenharia de Materiais da UFSCAR, (1996).

2. Toitzsch, J.; "International Plastic Flammability Handbook", Hanser Publishers, (1983).

3. Hilado,C. J.; Flammability Handbook for Electrical Insulation", Technomic Publishing Company, (1982).

4. Aseeva, R. M. e Zaikov, G. E.; "Combustion of polymer materials" Hanser Publishers, 1986.

5. Katz,H.S. e Milewski, J.V.; "Handbook of Fillers for plastics", Van Nostrand Reinhold Company, (1987).

6. Standard Practice for Assessment of Fire Risk by Occupancy Classification - ASTM E 931-85.

7. Nelson, G. L. "Testing of materials for fire Performance", Fire and Polymer Workshop of the ACS National Meeting, (1994).

\section{Leitura Recomendada}

1. Loughbrough, R. "Flame retardants, legislation fire market" Industrial Minerals,35-43, maio de 1991.

2. Stuart, W. A. "Will toxicity concerns doom workhorse flame retardant systems ?" Modern Plastics international, p 28 - 32, julho de 1990.

3. Musselman, L. L. "Alumina chemicals science and technology handbook" The Americam Ceramic Society, p 195 - 240, 1990.

4. "Tests for flammability of plastic materials for parts in devices and appliances "Underwriters Laboratories, UL94, 1992 .

5. "Standard test for specific optical densit of smoke generated by solid materials" ASTM E662, 1983.

6. "Standard test for measuring the oxigem index" ASTM D2863, 1987.
7. Cole, E. "Flame retardant polymer compositions" U.K. Patent Application GB 2231333A, (1990).

8. Kondo, M.;Toriumi,Y.; Akie,T.; Morishita,T.; Kawamoto,Y.; Ishise, K.; Fujioka, H. "Development of non-halogen flame retardant wire and cables (Part II)" Sumitomo Eletric Technical review, No 15, p 30 - 34 , (1985).

9. Seiho, T.; Yuichiro, S. e Tadashi, Y. "Flame retardant additives based on alumina trihydrate and ethylene polymer compositions, containing same, having improuved FR properties" European Patent Application 0077055A1, (1983).

10. Nakae, H.; Noguchi, I. e Hasebe,M. "Polyethylene composition densely filled with inorgânic material" U.K. Patent Application GB 2041960A, (1980).

11. "Flame retardants, Processors learn to work with halogen free systems" Modern Plastics International, p 39, (1993).

12. Christopher, A.J. "Effects of additives on fire properties of polyethylene" Fire and Materials, V 12, p 7 - 18, (1988).

13. Salman, S. e Klempner, D. "ATH may be moving in as a flame retardant filler for termoplastics" Plastic Engineering, (1979).

14. Gorbatsevich, G.M.; Fedeev, S.S. e Bogdanova,V.V. "Use of alumina trihydrate as a flame retardant for polyolefins" Plast. Massy, No 4, p 50 - 52, (1988).

15. "Smoke and toxicity: New trial by fire for plastics" Plastic World, (1976).

16. "Anti-Br flame retardants issue smoulders on" Industrial Minerals, p17, (1995).

17. "Flame retardants minerals, Bromine issue smoulders on" Industrial Minerals, p29, (1996).

18. Kirschbaum, G. S. " Recent developments in ATH and Magnesium Hydroxides - a chalenge to traditional materials" The Fire Retardant Chemicals Association, 1995 Fall conference, p145. 
Polímeros: Ciência e Tecnologia - Jan/Mar - 98 